\title{
Characteristics of Positive Surges in a Rectangular Channel
}

\author{
Feidong Zheng ${ }^{1,2} \mathbb{D}$, Yun $\mathrm{Li}^{1,3, *}$, Guoxiang Xuan ${ }^{1,3}$, Zhonghua Li ${ }^{1,3}$ and Long Zhu ${ }^{1,3}$ \\ 1 Nanjing Hydraulic Research Institute, Nanjing 210029, Jiangsu, China; feidongzheng@126.com (F.Z.); \\ xuan@nhri.cn (G.X.); zhli@nhri.cn (Z.L.); zhulong@nhri.cn (L.Z.) \\ 2 College of Water Conservancy and Hydropower Engineering, Hohai University, Nanjing 210098, \\ Jiangsu, China \\ 3 State Key Laboratory of Hydrology-Water Resources and Hydraulic Engineering, Nanjing 210029, \\ Jiangsu, China \\ * Correspondence: yli_nhri@126.com; Tel.: +86-025-8582-8022
}

Received: 17 September 2018; Accepted: 16 October 2018; Published: 19 October 2018

\begin{abstract}
A positive surge is an unsteady open channel flow motion characterized by an increase of flow depth. In previous experimental studies, a positive surge was typically induced by either a sudden increase of discharge in a channel or by the rapid closure of a downstream sluice gate, thus leading to a steep initial profile. However, in many instances, the evolution of a positive surge is of a progressive manner (e.g., in the downstream navigation canal during the emptying operation of lock chambers). In the present work, the inception and development of a positive surge induced by a progressive increase of discharge was investigated in a rectangular channel with a smooth bed. Both undular and breaking surges were studied. The results demonstrate that the maximum wave height at the first wave crest of an undular surge is in very close agreement with the McCowan theory. Additionally, the wave amplitude essentially shows a linearly increasing trend with an increasing surge Froude number up to $F r_{0}=1.26$ to 1.28 , whereas it tends to suggest a power law reduction for larger surge Froude numbers. Moreover, the dispersion of undular surges is consistent with the linear wave theory only for surge Froude numbers close to unity. Overall, the present study demonstrates the unique features of positive surges induced by a progressive increase of discharge.
\end{abstract}

Keywords: undular surge; breaking surge; progressive; dispersion characteristics; surge Froude number

\section{Introduction}

A positive surge is an unsteady open channel flow motion characterized by an increase of flow depth [1]. Positive surges are widely observed in man-made and natural channels. They may be induced by the emptying of lock chambers during lock operations [2] or by sluice gates installed along water supply canals for irrigation and power purposes [3]. For some flow conditions, the front of a positive surge is followed by a train of undulations (i.e., an undular surge) and even behaves as a nearly vertical water wall (i.e., a breaking surge). The passage of undular and breaking surges is associated with significant variations in hydrodynamics (i.e., flow velocity, water level and Reynolds stresses), and therefore they can be expected to affect the mixing and advection processes of sediments in channels [4,5]. In the case of navigation channels, these surges also potentially influence tow's maneuverability, thereby affecting the navigation safety and functional efficiency of locks [6].

The first systematic study of positive waves was performed by Favre [7], who investigated the characteristics of undular surges in a rectangular flume. In the experimental studies of Benet and Cunge [8], and Treske [6], the focus was on the properties of both undular and breaking surges in 
trapezoidal channels. New experiments were carried out by Soares Frazão and Zech [9] to investigate the characteristics of undular surges and to validate the proposed numerical scheme. More recent experimental work of the same kind has been performed by Chanson and co-workers [10-15]. Koch and Chanson [10] focused on the free-surface and turbulent flow properties of both undular and breaking surges. Hydraulic studies by Chanson [11] and Gualtieri and Chanson [12] were mostly concerned with the effect of bed roughness on the wave height attenuation and dispersion of an undular surge. An attempt was made by Chanson [13] to compare the free-surface profile of the undulations with both the sinusoidal and cnoidal wave functions. In the studies by Gualtieri and Chanson [14] and Leng and Chanson [15], the free-surface properties were compared to the analytical solutions of Lemoine [16] and Anderson [17], based on the linear wave theory and the Boussinesq equations, respectively. In some other studies, the upstream propagation of positive surges in a sloping rectangular channel was also investigated [18].

Undular and breaking surges in previous experimental studies have typically been generated in two different ways. One way is to induce a sudden increase in discharge in a channel, while another way is to generate undular and breaking surges by the rapid closure of a downstream sluice gate, thus leading to steep initial water profiles. However, in many instances, these surges occurred in a progressive manner. For example, in the case of the emptying operation of lock chambers, a positive surge with a rather smooth water profile is first generated in the downstream channel; subsequently, the front of the positive surge steepens and undulations slowly grow at the front head during propagation; and finally, an undular surge with some breaking or a breaking surge may form, depending on the flow conditions.

This work is focused on the inception and development of a positive surge induced by the progressive opening of an upstream plate gate. The free-surface characteristics were systematically investigated during the downstream propagation of positive surges.

\section{Experimental Setup and Experiment}

The experimental arrangement is schematically shown in Figure 1. The experimental facility consisted of a rectangular upstream reservoir, a rectangular flume and a pipeline connecting the two parts together. Both the length and width of the upstream reservoir were $1 \mathrm{~m}$. The horizontal channel was made of a smooth poly (vinyl chloride) (PVC) bed and Plexiglass sidewalls, $38 \mathrm{~m}$ long and $0.3 \mathrm{~m}$ wide, with a height of $0.35 \mathrm{~m}$. The flume was connected to a pipeline of the same width with a curved entrance at the upstream end of the channel bed. The downstream end of the flume was closed by a vertical rigid wall. The pipeline system was equipped with a plate gate and its shaft. The width and height of the gate were $0.3 \mathrm{~m}$ and $0.1 \mathrm{~m}$, respectively. The gate was driven vertically by a stepper motor, which could be used to exactly reproduce any desirable opening function. The total traveling height of the gate was equal to its height.

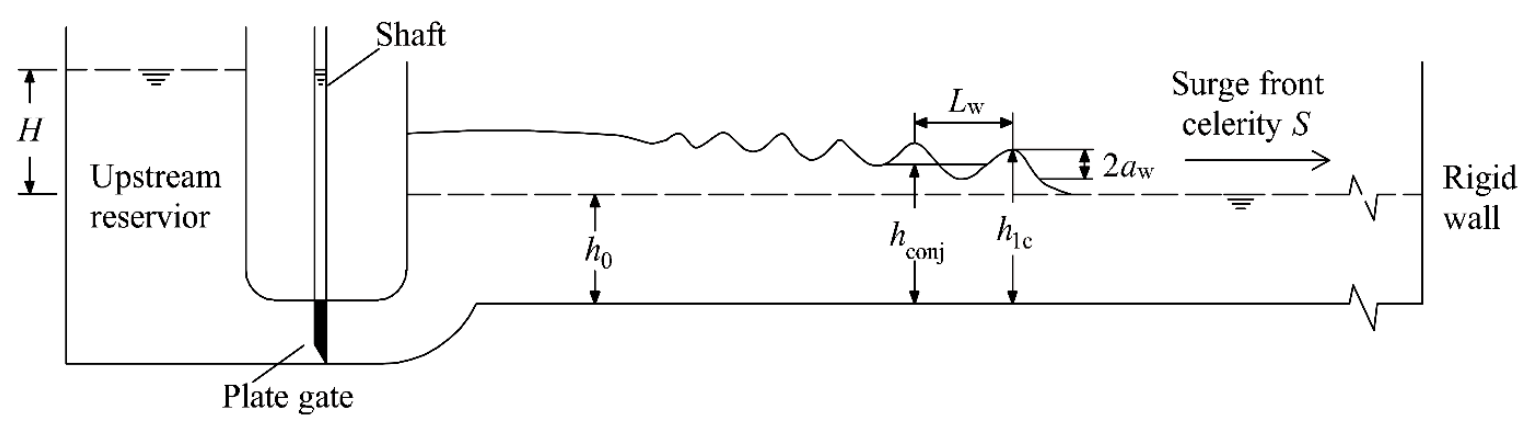

Figure 1. Sketch of the experimental facility.

The initial flow depths were recorded with point gauges in the upstream reservoir and the channel. The unsteady water depth in the channel was measured using a set of displacement meters spaced along the channel centerline, and a sampling frequency of $200 \mathrm{~Hz}$ was used for all the measurements. 
For all experiments, flow measurements were started $60 \mathrm{~s}$ before the gate opening, and were stopped when the surge reached the downstream rigid wall to avoid wave reflection interference.

It was assumed that the plate gate was raised at a constant speed until complete gate opening. The drop height $H$ was defined as the initial difference in elevation between the water surfaces of the upstream reservoir and the channel. Hydraulic considerations indicated that the unsteady water depth $h$ in the channel should essentially depend on the initial water depth in channel $h_{0}$, the drop height $H$, and the amount of time needed to fully open the gate $t_{\mathrm{v}}$. In the present study, the initial water depth in the channel was set to $8 \mathrm{~cm}$ by referring to the studies of Treske [6] and Koch and Chanson [10]. A summary of the experimental measurements is shown in Table 1. Overall, a large number of experimental runs were carried out in four series, denoted as A, B, C, and D, corresponding to four different times taken to fully open the gate of 20,25,30, and $40 \mathrm{~s}$ with four different drop heights. The experimental conditions were selected to generate both undular and breaking surges, taking into account the influence of undulation shape deviations on the characteristics of surges with close Froude numbers, which is defined in the system of coordinates in translation with the surge and is given by

$$
F r_{0}=\frac{S}{\sqrt{g h_{0}}}
$$

where $S$ = surge front celerity positive downstream and $g$ = gravity acceleration .

Table 1. Experimental series.

\begin{tabular}{cccc}
\hline Series & $\boldsymbol{h}_{\mathbf{0}}(\mathbf{m})$ & $\boldsymbol{t}_{\mathbf{v}}(\mathbf{s})$ & $\boldsymbol{H}(\mathbf{m})$ \\
\hline $\mathrm{A}$ & 0.08 & 20 & $0.1,0.2,0.3,0.4$ \\
$\mathrm{~B}$ & 0.08 & 25 & $0.1,0.2,0.3,0.4$ \\
$\mathrm{C}$ & 0.08 & 30 & $0.1,0.2,0.3,0.4$ \\
$\mathrm{D}$ & 0.08 & 40 & $0.1,0.2,0.3,0.4$ \\
\hline
\end{tabular}

\section{Results and Discussion}

\subsection{Basic Flow Patterns}

A positive surge was generated in the flume by raising the plate gate at a constant speed. During the downstream propagation of the positive surge, different wave types may occur at the front head. Here, the overall developing processes observed at the front of positive surges have been consolidated into four major flow stages, and are described below. It should be noted that the number of flow stages for each experimental run was variable, depending on the drop height and the time taken to fully open the gate.

- In Stage 1, the front of the positive wave is rather smooth.

- Stage 2 corresponds to the generating process of the undular surges, and can be divided into two sub-stages: Stage2a and Stage2b. In Stage 2a, the front head of the positive wave gradually becomes "rough" and develops into a series of cascading steps at the end of this stage; in Stage $2 b$, the cascading steps develop into a train of well-formed undulations (i.e., non-breaking undular surges) (Figure 2). Additionally, some sidewall shock waves can be observed in this stage that develop upstream of the first wave crest and intersect next to the first crest. This stage ends when some small waves break at the first wave crest (i.e., breaking undular surges) (Figure 3).

- In Stage 3, the wave amplitude decreases and the free-surface undulations become flatter. This stage ends with the disappearance of fluctuating characteristics of water depth at the surge front.

- During Stage 4, the surge front behaves as a nearly vertical water wall (i.e., breaking surges) (Figure 4). 


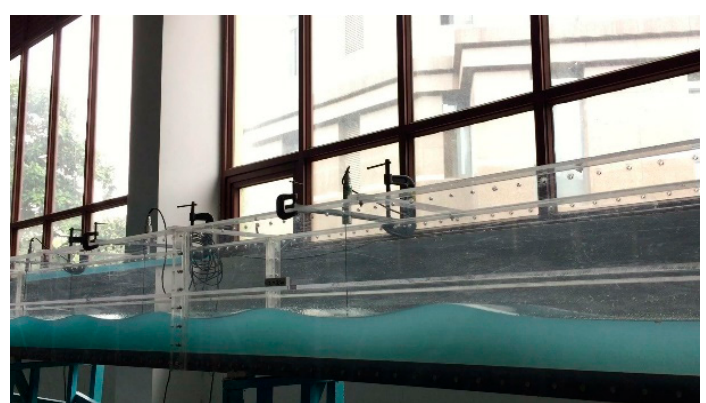

(a)

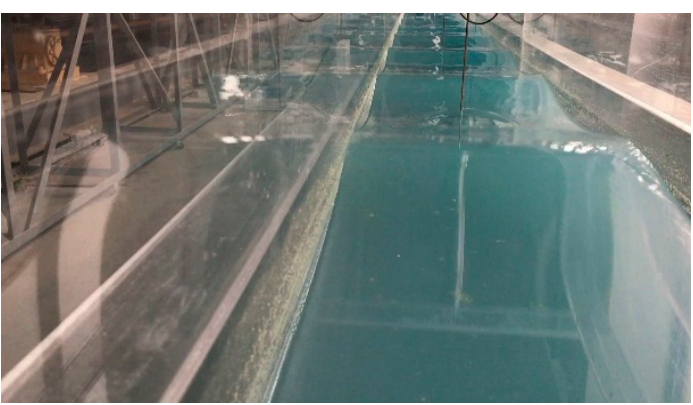

(b)

Figure 2. Non-breaking undular surges in Stage 2b: (a) Lateral view; (b) looking upstream at the incoming wave.

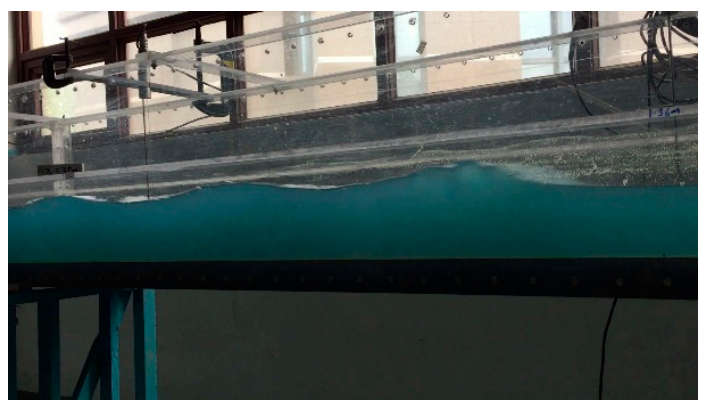

(a)

Figure 3. Breaking undular surges in Stage 3: incoming wave.

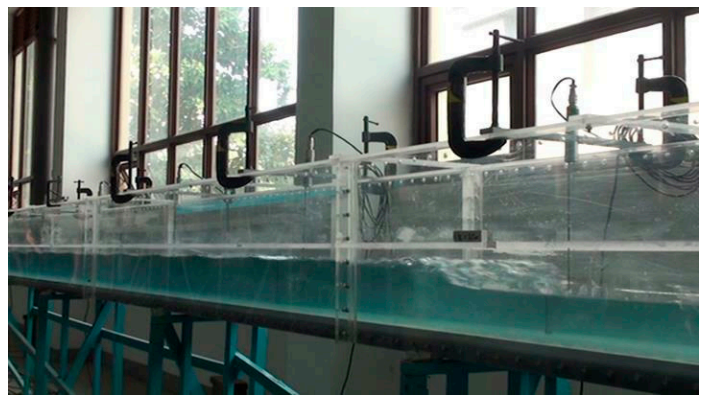

(a)

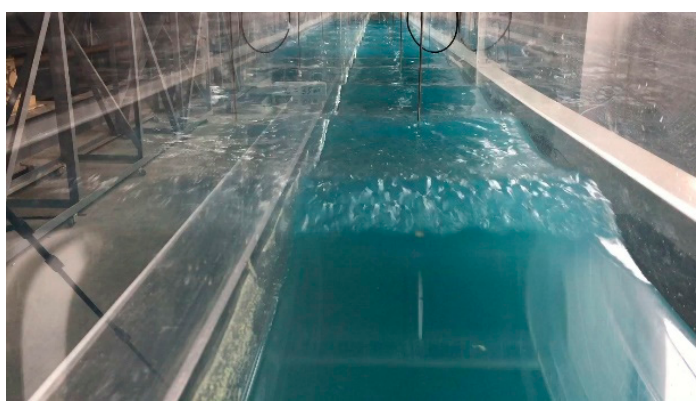

(b)

(a) Lateral view; (b) looking upstream at the

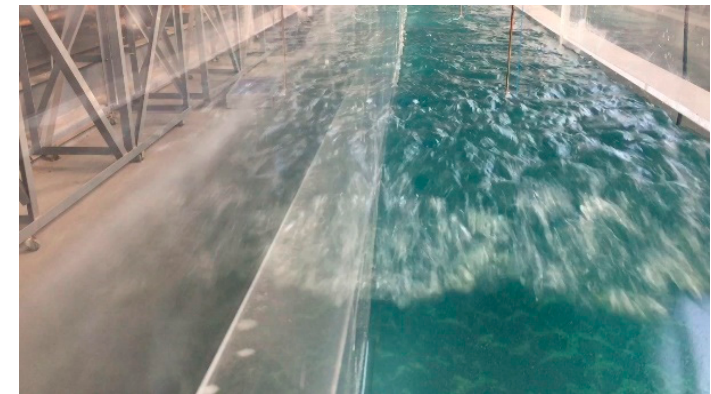

(b)

Figure 4. Breaking surges in Stage 4: (a) Lateral view; (b) looking upstream at the incoming wave.

The tests indicate that transitions between different flow stages can be characterized solely with the surge Froude number (Table 2). Moreover, the surge Froude numbers corresponding to these transitions are close to those of Chanson [11,13] and Leng and Chanson [15] for both smooth and rough beds, although these studies focused on the positive surges induced by the rapid closure of a downstream sluice gate.

Table 2. Surge Froude number values for flow stage transitions.

\begin{tabular}{cc}
\hline Flow Stage Transition & Surge Froude Number $\boldsymbol{F r}_{\mathbf{0}}$ \\
\hline $1-2 \mathrm{a}$ & $\approx 1.03$ \\
$2 \mathrm{a}-2 \mathrm{~b}$ & $1.07-1.10$ \\
$2 \mathrm{~b}-3$ & $1.26-1.28$ \\
$3-4$ & $1.45-1.50$ \\
\hline
\end{tabular}




\subsection{Free-Surface Properties}

\subsubsection{Ratio of Conjugate Depths}

In a rectangular horizontal channel, when neglecting friction loss, the combined application of the continuity and momentum equations across the surge front yields

$$
\frac{h_{\text {conj }}}{h_{0}}=\frac{1}{2}\left(\sqrt{1+8 F r_{0}^{2}}-1\right)
$$

where $h_{\text {conj }}$ and $h_{0}$ are the conjugate and initial depths, respectively. Equation (2) is the famous Bélanger equation. In the present study, the conjugate depth $h_{\text {conj }}$ was defined as the average of the first wave crest and the trough depths for the undular surges, while it was the water depth immediately behind the surge front for breaking surges. The ratio of conjugate depths, $h_{\text {conj }} / h_{0}$, is plotted against the surge Froude number, $F r_{0}$, in Figure 5 for both undular and breaking surges. Although the experimental trend is comparable to that produced by Equation (2), the entire dataset shows generally higher values of $h_{\text {conj }} / h_{0}$ for $1.07<F r_{0}<1.57$. This may be partially attributed to the uncertainty of estimating the conjugate depth; that is, in the undular surges, the conjugate depth was calculated based on a symmetrical undulation profile which is inconsistent with the experimental data, while the measurement of the conjugate depth was affected adversely by the large free-surface fluctuations behind the surge front in the breaking surges. It is worth noting that the data in flow Stage $2 \mathrm{~b}$ are more scattered than in flow Stages 3 and 4 for a given surge Froude number, which might imply larger deviations of wave shapes for non-breaking surges than for breaking undular and breaking surges.

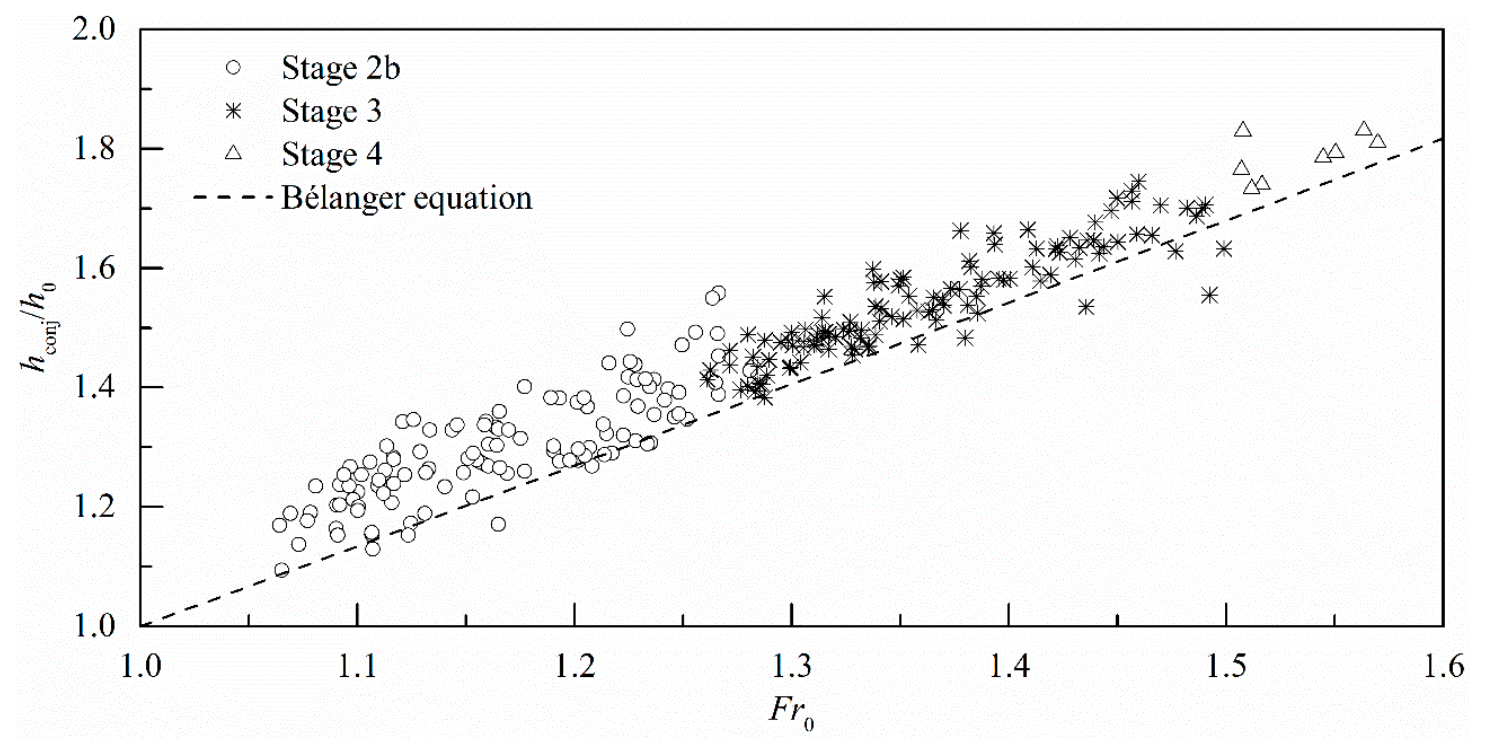

Figure 5. Variation of $h_{\text {conj }} / h_{0}$ with $F r_{0}$ for both undular and breaking surges.

\subsubsection{Free-Surface Undulation Characteristics}

(1) Wave height of the first wave crest

The wave height of the first wave crest $\left(h_{1 \mathrm{c}}-h_{0}\right)$ is plotted in a dimensionless form against $F r_{0}$ in Figure 6. For non-breaking undular surges in Stage $2 b$, the values of $\left(h_{1 c}-h_{0}\right) / h_{0}$ show a trend of linear increase with $F r_{0}$ in general. For breaking undular surges in Stage 3, a sharp decrease in wave height is observed shortly after the appearance of some wave breaking at the first wave crest, and subsequently, $\left(h_{1 \mathrm{c}}-h_{0}\right) / h_{0}$ exhibits the same increasing trend as the data in flow Stage $2 \mathrm{~b}$, but at a much smaller rate. It is worth noting that in flow Stage $2 b,\left(h_{1 c}-h_{0}\right) / h_{0}$ is close to the solitary wave theory for surge Froude numbers $F r_{0}$ less than 1.1, while the data show consistently higher values of $\left(h_{1 \mathrm{c}}-h_{0}\right) / h_{0}$ for larger surge Froude numbers. 


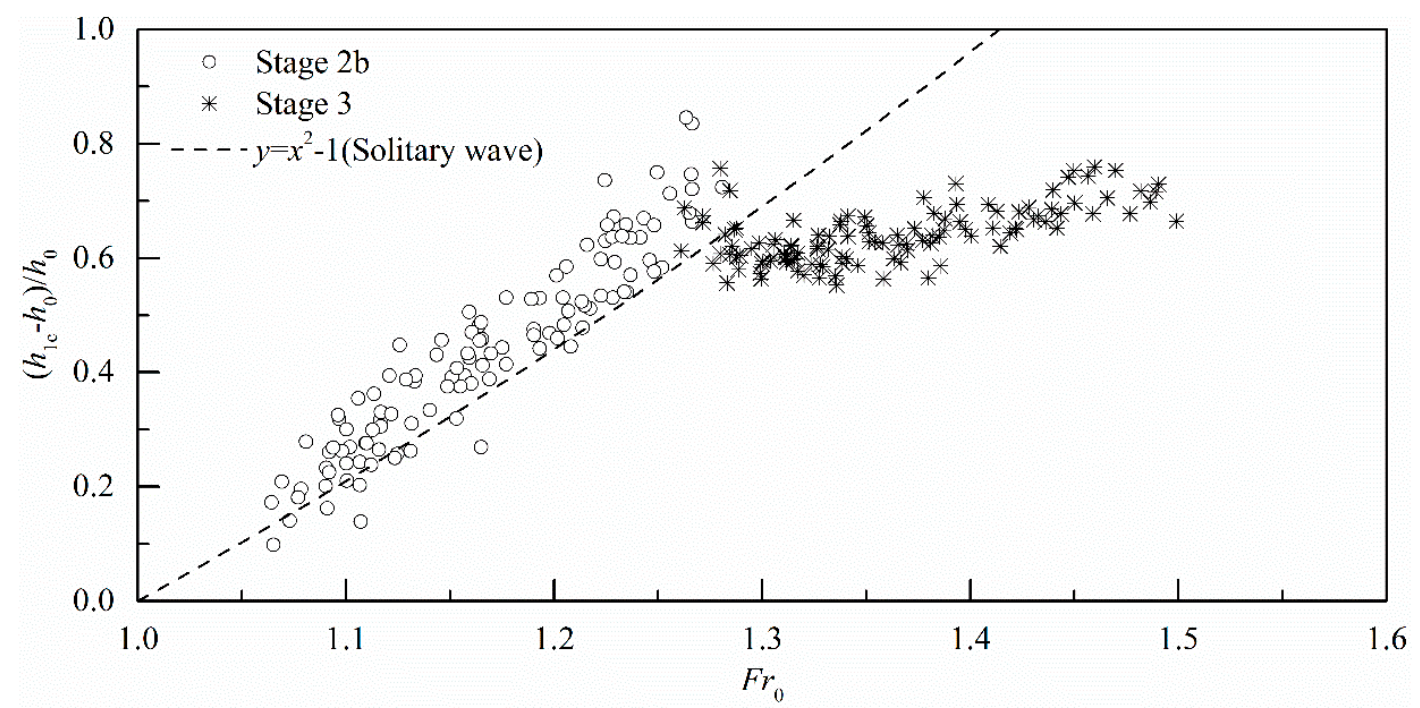

Figure 6. Variation of $\left(h_{1 \mathrm{c}}-h_{0}\right) / h_{0}$ with $F r_{0}$ for undular surges.

The wave height data of the first wave crest are further compared with previous experimental studies in Figure 7. It is found that present data are consistent with the trend observed by Peregrine [19], Koch and Chanson [10] and Chanson [11]. In Figure 7, the data are also compared with the McCowan theory, which shows the maximum wave heights attained by solitary waves. It can be seen that there is an excellent agreement between this paper's results and McCowan's theory [20].

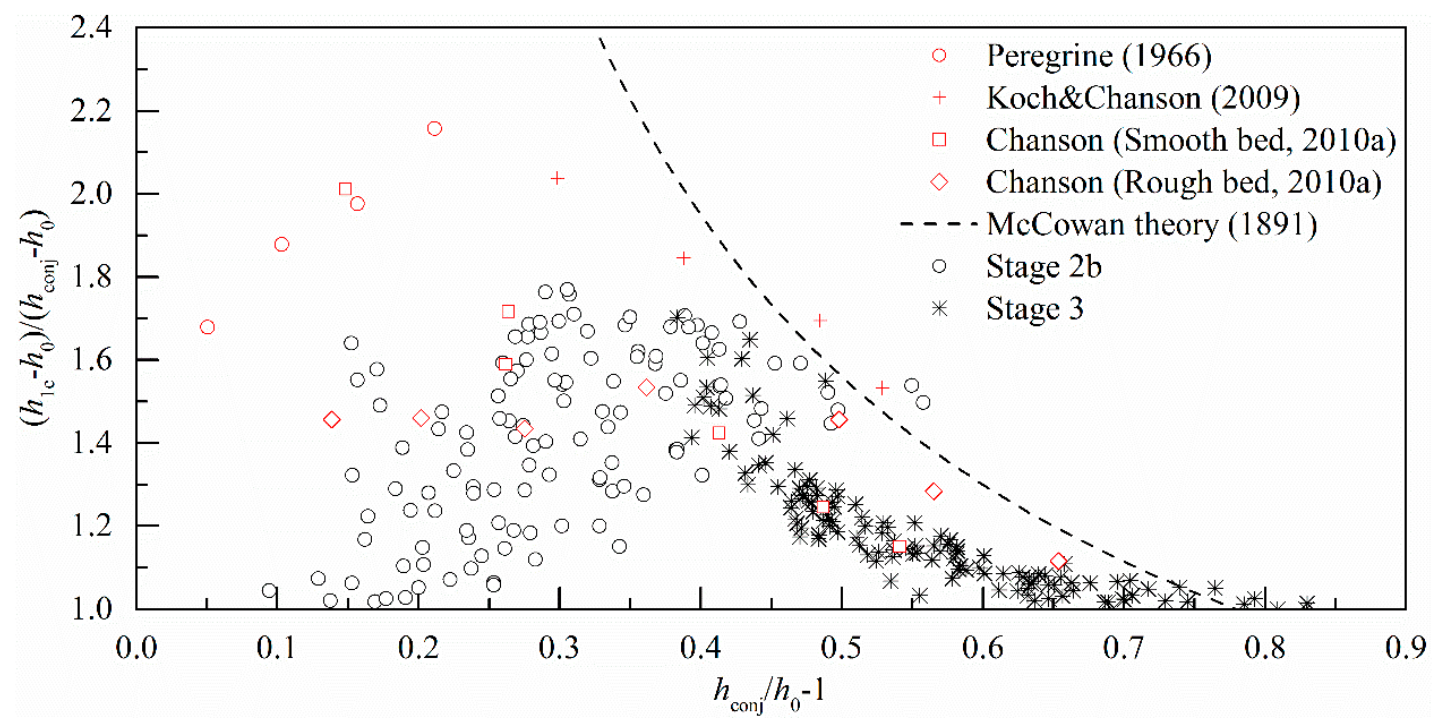

Figure 7. Wave height at the first wave crest for undular surges.

(2) Wave amplitude, length and steepness

The wave amplitude, length and steepness are shown in Figure 8 in dimensionless forms (i.e., $a_{\mathrm{w}} / h_{0}, L_{\mathrm{w}} / h_{0}$, and $a_{\mathrm{w}} / L_{\mathrm{w}}$ ). Both wave amplitude and wave length were calculated according to the definitions by Koch and Chanson [10]; that is, the wave amplitude, $a_{\mathrm{w}}$, was half of the difference between the water depth at the first wave crest and at the first wave trough, while the wave length, $L_{\mathrm{W}}$, was defined between the first and second crests. The data are compared with the linear wave theory solution of Lemoine, the Boussinesq equation solution of Anderson, earlier experimental studies and field observations [21-23]. 


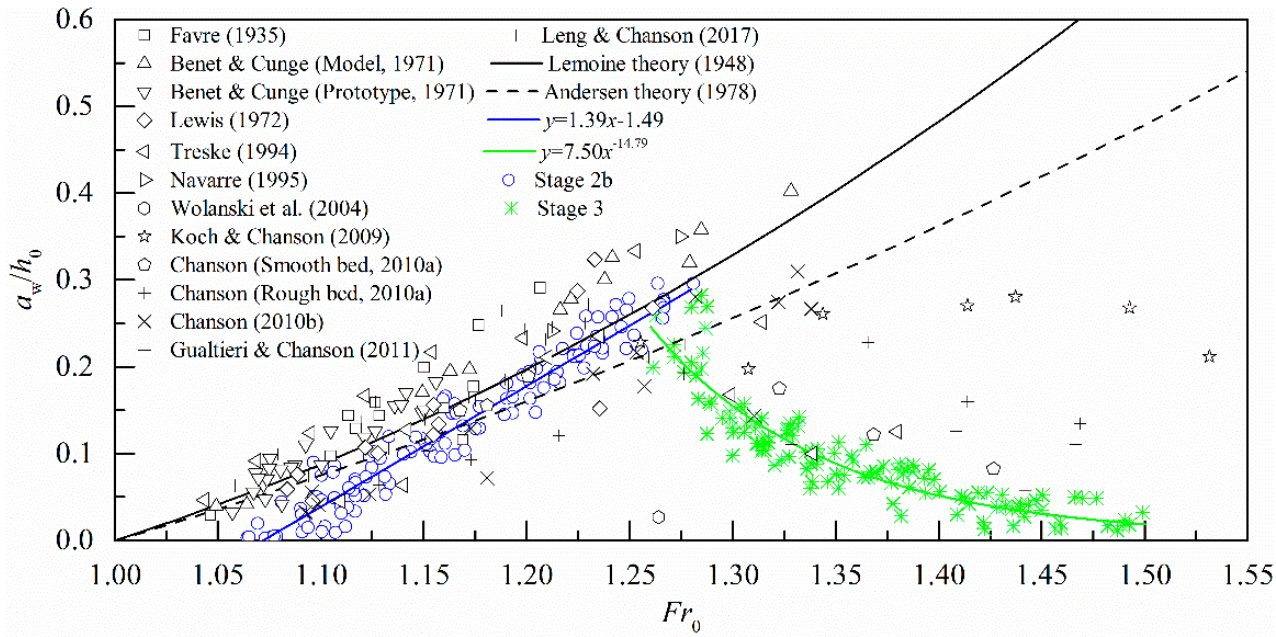

(a)

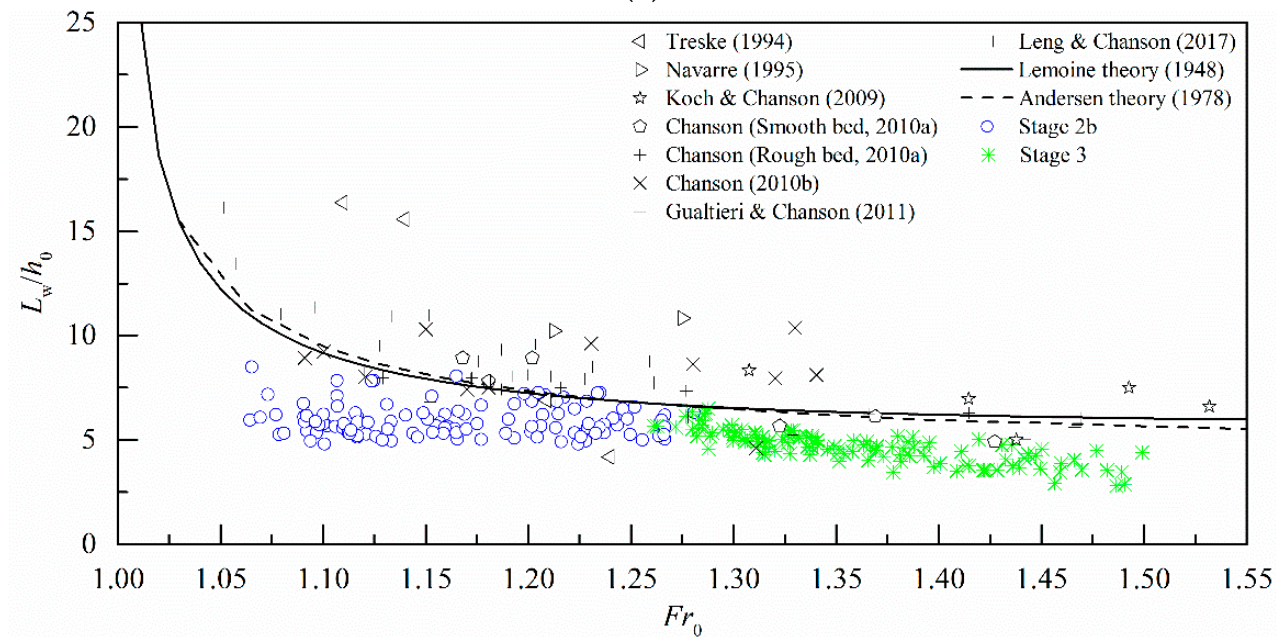

(b)

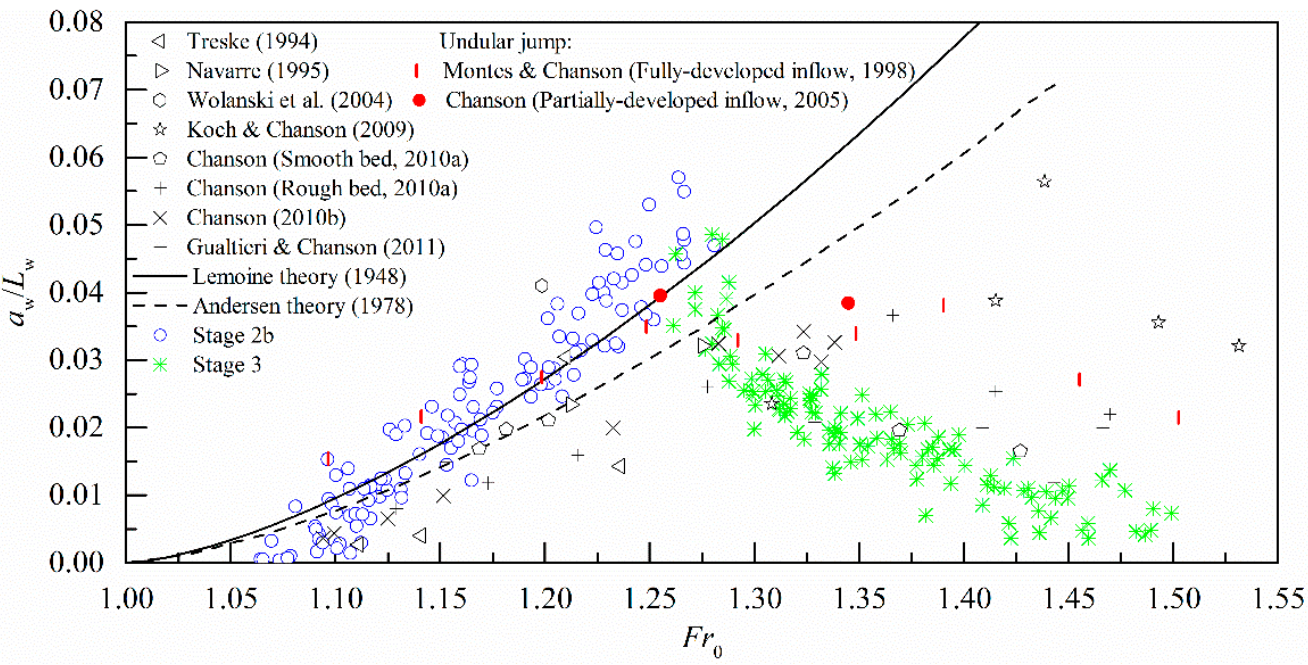

(c)

Figure 8. Characteristics of undular surges as functions of $F r_{0}$ : (a) Dimensionless wave amplitude $a_{\mathrm{w}} / h_{0} ;(\mathbf{b})$ dimensionless wave length $L_{\mathrm{w}} / h_{0} ;(\mathbf{c})$ wave steepness $a_{\mathrm{w}} / L_{\mathrm{w}}$.

It can be seen from Figure 8a that the wave amplitude increases monotonically with an increasing surge Froude number to a local maximum for non-breaking undular surges in Stage 2b. However, 
an abrupt decrease in wave amplitude is observed immediately after the appearance of wave breaking at the first wave crest for breaking undular surges in Stage 3; subsequently, a gradual declining trend was held before the disappearance of free-surface undulations. The relationship between $a_{\mathrm{w}} / h_{0}$ and $F r_{0}$ for undular surges is well described by the following equations

$$
\begin{aligned}
& \frac{a_{\mathrm{w}}}{h_{0}}=1.39 F r_{0}-1.49 \text { for } 1.07-1.10<F r_{0}<1.26-1.28 \\
& \frac{a_{\mathrm{w}}}{h_{0}}=7.50 F r_{0}{ }^{-14.79} \text { for } 1.26-1.28<F r_{0}<1.45-1.50
\end{aligned}
$$

Overall, the present data exhibit a qualitative agreement with all previous studies, as indicated in Figure 8a. Moreover, although neither the linear wave theory nor the Boussinesq equation solution can accurately predict the wave amplitude before surge breaking, the data tend to get close to Lemoine's solution for surge Froude numbers in the range of 1.2 to 1.28 .

The dimensionless wave length data are shown in Figure $8 \mathrm{~b}$. Although the experimental trend is close to that predicted by the theories of both Lemoine and Anderson and earlier experimental studies, the data show consistently lower wave lengths, especially for very low or high Froude numbers.

Figure $8 \mathrm{c}$ presents the dimensionless wave steepness data. It can be seen that the wave steepness exhibits a similar trend to wave amplitude $-a_{\mathrm{w}} / L_{\mathrm{w}}$ shows an increasing and decreasing trend for non-breaking and breaking undular surges, respectively. Additionally exhibited in this figure are the data sets obtained in undular hydraulic jumps [24,25]. For surge Froude numbers less than 1.29, the present data set is in excellent agreement with undular jump data.

\section{(3) Dispersion characteristics}

The undular surges investigated in this study have the property of net mass transport, which is in conjunction with the finite amplitude water waves [26]. For a finite amplitude wave, the linear wave theory yields a dispersion relationship between the wave length $L_{\mathrm{w}}$, wave period $T$ and water depth $h$ :

$$
L_{\mathrm{w}}=\frac{g T^{2}}{2 \pi} \tanh \left(\frac{2 \pi h}{L_{\mathrm{w}}}\right)
$$

However, the undular surge is typical of a translation wave, i.e., water particles underneath the water surface do not move backwards, indicating marked differences between undular surges and finite amplitude waves. Therefore, a dimensionless dispersion parameter $D$ can be defined for undular surges as

$$
D=L_{\mathrm{w}} /\left(\frac{g T^{2}}{2 \pi} \tanh \left(\frac{2 \pi h_{\text {conj }}}{L_{\mathrm{w}}}\right)\right)
$$

Plots of $D$ versus $F r_{0}$ for undular surges are presented in Figure 9. It is shown that a definite correlation exists between the two dimensionless variables, with essentially no influence of undular surge types. In the experimental range $1.07<F r_{0}<1.50$, the following empirical equation can be proposed by fitting both data sets (i.e., for non-breaking and breaking undular surges)

$$
D=0.046 \exp \left(2.952 F r_{0}\right)
$$

It is clearly demonstrated that for a surge Froude number $F r_{0}$ less than 1.1, the dispersion parameter $D$ is close to 1 , and hence the dispersion relationship based on the linear wave theory is assumed to hold.

\subsubsection{Energy and Momentum Fluxes Properties}

A positive surge is seen as a quasi-steady flow situation by an observer travelling at the surge speed $S$. In a rectangular, horizontal channel, if both the rate of energy dissipation and friction loss are negligible, the equations of conservation of energy and momentum can be rewritten as [26] 


$$
\begin{aligned}
E^{*} & =\frac{E}{h_{\mathrm{c}}}=\frac{h}{h_{\mathrm{c}}}+\frac{1}{2}\left(\frac{h_{\mathrm{c}}}{h}\right)^{2}=\mathrm{const} \\
M^{*} & =\frac{M}{h_{\mathrm{c}}^{2}}=\frac{h_{\mathrm{c}}}{h}+\frac{1}{2}\left(\frac{h}{h_{\mathrm{c}}}\right)^{2}=\mathrm{const}
\end{aligned}
$$

where $E$ is the specific energy; $M$ is the specific momentum; $h$ is the flow depth; $E^{*}$ and $M^{*}$ correspond to the dimensionless specific energy and specific momentum, respectively; and $h_{\mathrm{c}}$ is the critical depth in the system of coordinates in translation with the undular surge front, and is defined as

$$
h_{\mathrm{c}}=\sqrt[3]{S^{2} h_{0}^{2} / g}
$$

This pair of equations may be viewed as the parametric representation of $M^{*}=f\left(E^{*}\right)$, with $h / h_{\mathrm{c}}$ as a parameter. The function $E^{*}-M^{*}$ has two branches (the red dash line in Figure 10), intersecting at $(1.5,1.5)$. The lower branch of the curve $E^{*}-M^{*}$ corresponds to a supercritical flow while the upper branch represents a subcritical flow. Figure 10 shows a comparison of $M^{*}=f\left(E^{*}\right)$ and the entire dataset in this study. It is expected that the initial flow data are located on the supercritical branch while the corresponding conjugate flow data are on the subcritical branch. It can also be concluded from Figure 10 , that at the subcritical branch of the curve $E^{*}-M^{*}$, some overlaps exist between regions corresponding to different flow stages, indicating marked differences between travelling positive surges and stationary hydraulic jumps [27].

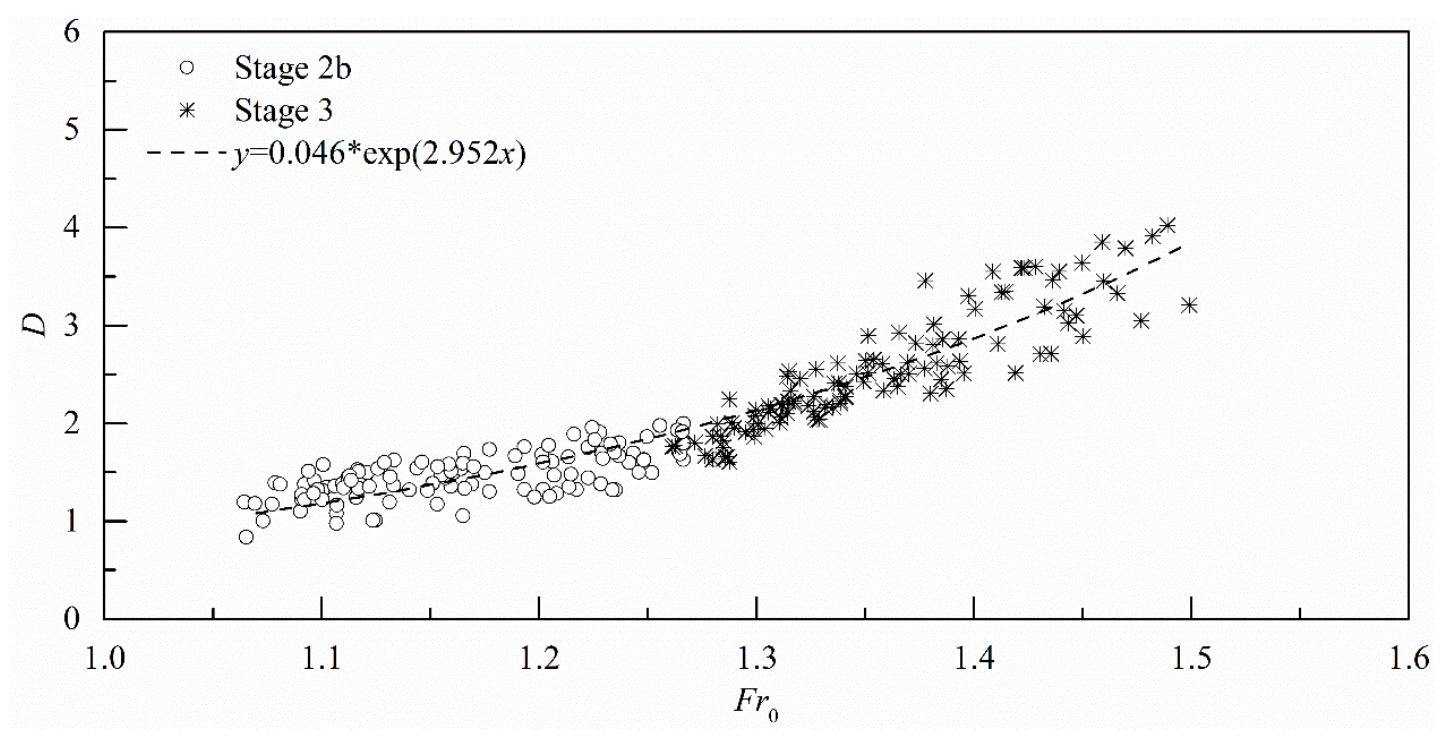

Figure 9. Variation of $D$ with $F r_{0}$ for undular surges.

Figure 11 shows a comparison of the dimensionless specific energy in the initial flow $\left(E_{0}^{*}\right)$ and the corresponding conjugate flow $\left(E_{\text {conj }}{ }^{*}\right)$. It can be found that the values of $E_{\text {conj }}{ }^{*}$ are basically larger than that of $E_{0}^{*}$ for non-breaking undular surges in Stage $2 \mathrm{~b}$. This is probably due to the pressure distribution beneath an undular surge that is less than hydrostatic beneath the wave crest and greater than hydrostatic beneath the wave trough. With the ensuing development of undular surges, $E_{\text {conj }}{ }^{*}$ approaches $E_{0}{ }^{*}$ for breaking undular surges in Stage 3 , and is essentially less than $E_{0}$ * for breaking surges in Stage 4 . This may be primarily attributed to energy dissipation due to wave breaking, and hence a smaller specific energy in the conjugated flow than in the initial flow is obtained in breaking surges.

In Figure 12, a comparison of the dimensionless specific momentum in the initial flow $\left(M_{0}^{*}\right)$ and the corresponding conjugate flow $\left(M_{\mathrm{conj}}{ }^{*}\right)$ is presented. The values of $M_{\text {conj }}{ }^{*}$ are consistently larger 
than that of $M_{0}{ }^{*}$ for the entire present test range. The main reason for this may be the deviation from the hydrostatic and the complicated velocity distribution in undular and breaking surges.

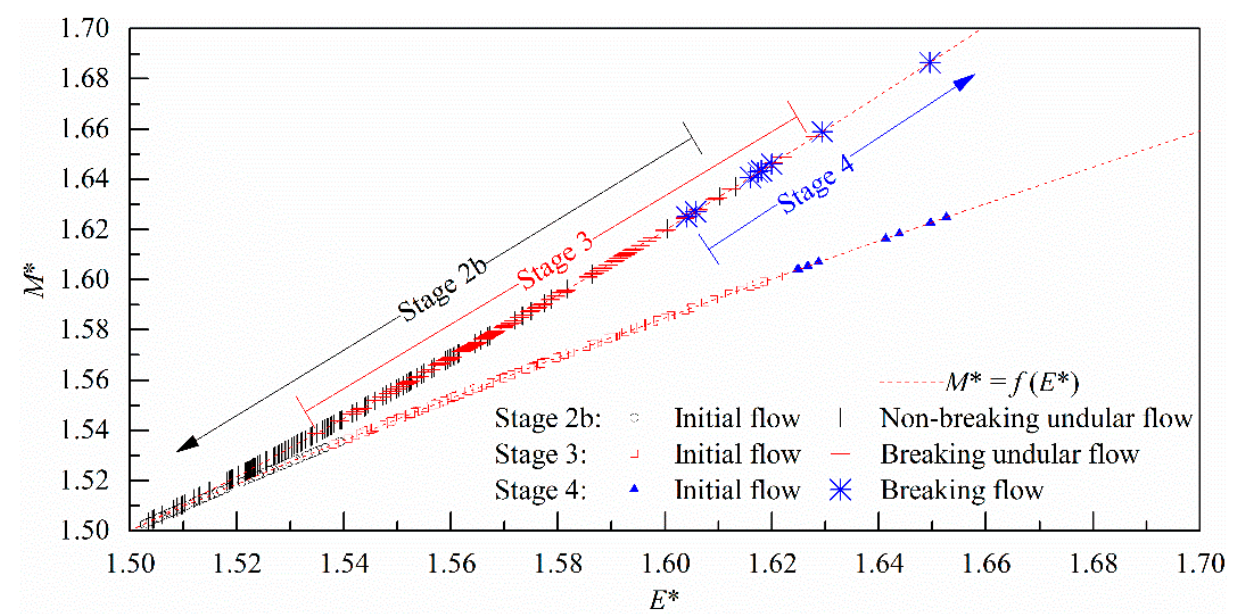

Figure 10. Dimensionless relationship between the momentum and energy fluxes for both undular and breaking surges.

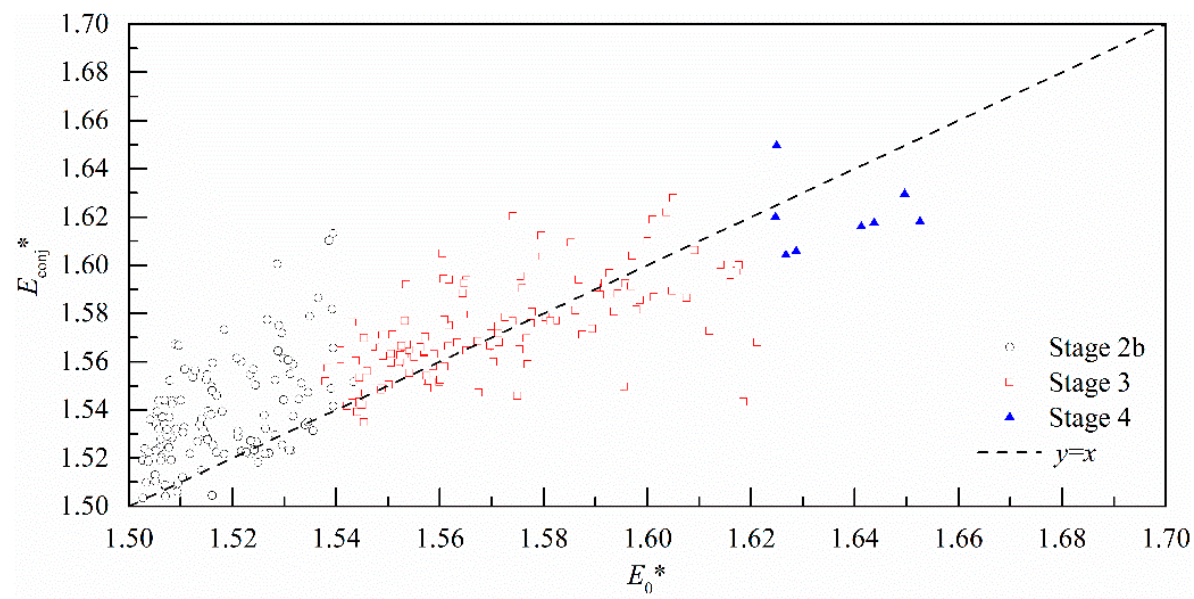

Figure 11. Comparison of $E_{0}{ }^{*}$ and $E_{\text {conj }}{ }^{*}$ for both undular and breaking surges.

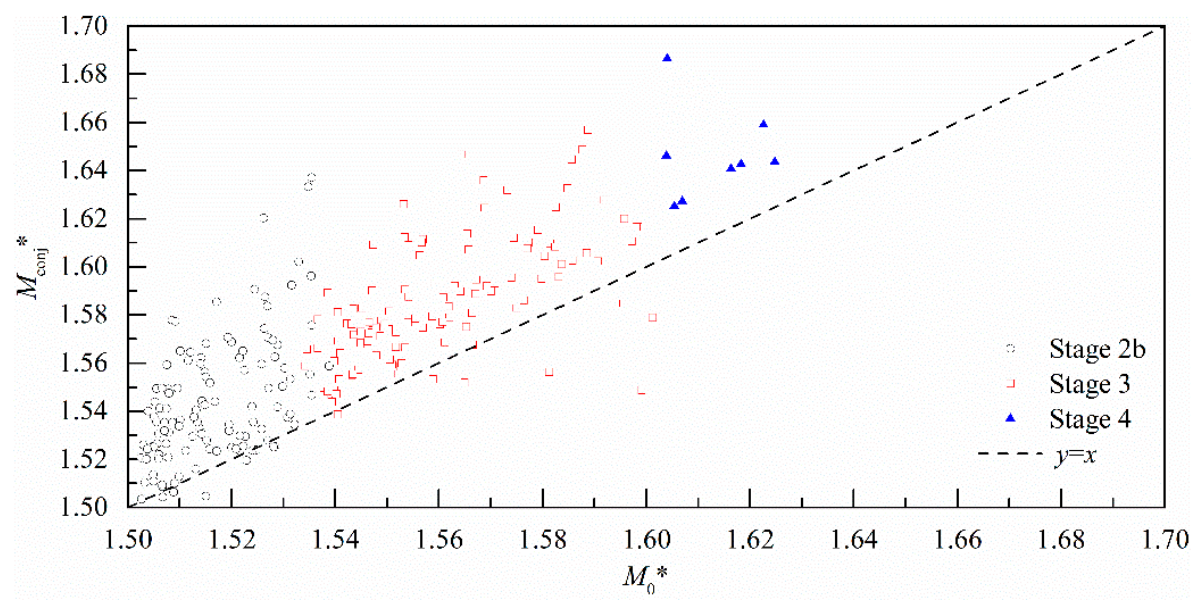

Figure 12. Comparison of $M_{0}{ }^{*}$ and $M_{\text {conj }}{ }^{*}$ for both undular and breaking surges. 


\section{Conclusions}

The free-surface properties of a positive surge induced by the progressive opening of an upstream plate gate were investigated experimentally in a rectangular channel with a smooth bed. Both undular and breaking surges were studied with a wide range of surge Froude numbers $F r_{0}$ ranging from 1.07 to 1.57. The occurrence of non-breaking undular surges was observed for 1.07-1.10 $<F r_{0}<1.26-1.28$, breaking undular surges for 1.26-1.28 $<F r_{0}<1.45-1.50$, and breaking surges for $F r_{0}>1.45-1.50$. The range of Froude numbers corresponding to each type of surge is consistent with previous findings $[11,13,15]$, although previous studies were concerned with positive surges induced by the rapid closure of a downstream sluice gate.

A detailed analysis of undular surge characteristics was conducted. First, during the propagation process of undular surges, the wave height of the first wave crest increases with the surge Froude number at a much greater rate for non-breaking undular surges than for breaking undular surges. Second, the maximum wave height of the first wave crest is in very close agreement with the McCowan theory. Third, neither the linear wave theory nor the Boussinesq equation solution can accurately predict the wave amplitude and steepness for small surge Froude numbers $\left(F r_{0}<1.26-1.28\right)$, and the wave length data are consistently lower than the values predicted from the above theories. Based on the experimental results, two empirical equations in terms of the surge Froude number were proposed to estimate wave amplitude. Fourth, the dispersion of undular surges is consistent with the linear wave theory only for surge Froude numbers close to unity $\left(F r_{0}<1.1\right)$, demonstrating marked differences with undular surges investigated in previous studies $[11,12]$. Therefore, a novel dimensionless parameter defined as $L_{\mathrm{w}} /\left[\left(g T^{2} / 2 \pi\right) \times \tanh \left(2 \pi h_{\text {conj }} / L_{\mathrm{w}}\right)\right]$ was introduced to characterize the dispersion of undular surges induced by a progressive increase of discharge and it was found to solely depend on the surge Froude number.

Furthermore, on the subcritical branch of the function $E^{*}-M^{*}$ proposed by Benjamin and Lighthill [27], the large overlaps of different data regions, corresponding to three different surge types, indicate some key differences between travelling positive surges and stationary hydraulic jumps. This study provides important data for the development and verification of numerical schemes for computing such positive surges. In the case of navigation canals, the present results may be applicable in assisting engineers to predict the characteristics of positive surges and further estimate the sudden surge loads on lock gates and navigation ships during the emptying operation of lock chambers.

Author Contributions: F.Z. performed experiments and wrote the paper; Y.L. and G.X. led the work performance and edited the manuscript; Z.L. and L.Z. collected data through the review of relevant literature.

Funding: This research was funded by the National Key R\&D Program of China (Grant No. 2016YFC0402003).

Acknowledgments: The authors would like to express their gratitude to Yue Huang and Xiujun Yan for their help and support in this experiment.

Conflicts of Interest: The authors declare no conflict of interest.

\section{References}

1. Henderson, F.M. Open-Channel Flow; McMillan Publishing Co.: New York, NY, USA, 1966.

2. Maeck, A.; Lorke, A. Ship-lock induced surges in an im-pounded river and their impact on subdaily flow velocity variation. River Res. Appl. 2013, 30, 494-507. [CrossRef]

3. Chanson, H. The Hydraulics of Open Channel Flows: An Introduction; Butterworth-Heinemann: Oxford, UK, 2004; p. 630.

4. Chen, C.L. Unified Theory on Power Laws for Flow Resistance. J. Hydraul. Eng. ASCE 1990, 117, 371-389. [CrossRef]

5. Kjerfve, B.; Ferreira, H.O. Tidal Bores: First Ever Measurements. Ciência e Cultura (J. Braz. Assoc. Adv. Sci.) 1993, 45, 135-138.

6. Treske, A. Undular bores (Favre-waves) in open channels-Experimental studies. J. Hydraul. Res. 1994, 32, 355-370. [CrossRef] 
7. Favre, H. Etude Théoretique et Expérimentale des Ondes de Translation Dans les Canaux Découverts (Theoretical and Experimental Study of Travelling Surges in Open Channels); Dunod: Paris, France, 1935.

8. Benet, F.; Cunge, J.A. Analysis of experiments on secondary undulations caused by surge waves in trapezoidal channels. J. Hydraul. Res. 1971, 9, 11-33. [CrossRef]

9. Soares-Frazão, S.; Zech, Y. Undular bores and secondary waves-Experiments and hybrid finite-volume modeling. J. Hydraul. Res. 2002, 40, 33-43. [CrossRef]

10. Koch, C.; Chanson, H. Turbulence measurements in positive surges and bores. J. Hydraul. Res. 2009, 47, 29-40. [CrossRef]

11. Chanson, H. Unsteady turbulence in tidal bores: Effects of bed roughness. J. Waterw. Port Coast. Ocean Eng. 2010, 136, 247-256. [CrossRef]

12. Gualtieri, C.; Chanson, H. Experimental study of a positive surge. Part 1: Basic flow patterns and wave attenuation. Environ. Fluid Mech. 2012, 12, 145-159. [CrossRef]

13. Chanson, H. Undular Tidal Bores: Basic Theory and Free-surface Characteristics. J. Hydraul. Eng. ASCE 2010b, 136, 940-944. [CrossRef]

14. Gualtieri, C.; Chanson, H. Experimental study of a positive surge. Part 2: Comparison with literature theories and unsteady flow field analysis. Environ. Fluid Mech. 2011, 11, 641-651. [CrossRef]

15. Leng, X.; Chanson, H. Upstream Propagation of Surges and Bores: Free-Surface Observations. Coast. Eng. J. 2017, 59, 1750003. [CrossRef]

16. Lemoine, R. Sur les ondes positives de translation dans les canaux et sur le ressaut ondulé de faible amplitude (On the Positive Surges in Channels and on the Undular Jumps of Low Wave Height). Jl La Houille Blanche 1948, 2, 183-185. (In French)

17. Andersen, V.M. Undular Hydraulic Jump. J. Hydraul. Div. ASCE 1978, 104, 1185-1188.

18. Viero, D.P.; Peruzzo, P.; Defina, A. Positive Surge Propagation in Sloping Channels. Water 2017, 9, 518-530. [CrossRef]

19. Peregrine, D.H. Calculations of the development of an undular bore. J. Fluid Mech. 1966, 25, 321-330. [CrossRef]

20. McCowan, J. On the solitary wave. Lond. Edinb. Dublin Philos. Mag. J. Sci. 1891, 32, 45-58. [CrossRef]

21. Lewis, A.W. Field Studies of a Tidal Bore in the River Dee. Master's Thesis, University College of North Wales, Bangor, UK, 1972.

22. Navarre, P. Aspects Physiques du Caracteres Ondulatoire duMacaret en Dordogne (Physical Features of the Undulations of the Dordogne River Tidal Bore). Ph.D. Thesis, University of Bordeaux, Bordeaux, France, 1995.

23. Wolanski, E.; Williams, D.; Spagnol, S.; Chanson, H. Undular tidal bore dynamics in the Daly Estuary, Northern Australia. Estuar. Coast. Shelf Sci. 2004, 60, 629-636. [CrossRef]

24. Montes, J.S.; Chanson, H. Characteristics of undular hydraulic jumps. Results and calculations. J. Hydraul. Eng. ASCE 1998, 124, 192-205. [CrossRef]

25. Chanson, H. Physical modelling of the flow field in an undular tidal bore. J. Hydraul. Res. 2005, 43, $234-244$. [CrossRef]

26. Montes, J.S. Hydraulics of Open Channel Flow; ASCE Press: New York, NY, USA, 1998.

27. Benjamin, T.B.; Lighthill, M.J. On cnoidal waves and bores. Proc. R. Soc. Lond. Ser. A 1954, 224, 448-460. [CrossRef]

(C) 2018 by the authors. Licensee MDPI, Basel, Switzerland. This article is an open access article distributed under the terms and conditions of the Creative Commons Attribution (CC BY) license (http:/ / creativecommons.org/licenses/by/4.0/). 